\title{
AVALIAÇÃO DE ARGAMASSAS MISTAS DE REVESTIMENTO PRODUZIDAS COM BORRACHA DE PNEUS
}

\author{
Nayra Alberici Pinto ${ }^{*}$, Cesar Fabiano Fioriti ${ }^{2}$

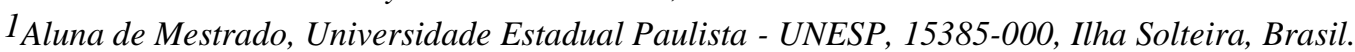 \\ ${ }_{2}^{2}$ Professor Doutor, Universidade Estadual Paulista-UNESP, 19060-900, Presidente Prudente, Brasil. \\ *E-mail:nayra_alberici@hotmail.com
}

Recebido em: 18/04/2016

Aceito em: 20/05/2016

\section{RESUMO}

Estudos sobre a produção de argamassas com incorporação de borracha de pneus demonstram a possibilidade deste material substituir, parcialmente, agregados de origem natural, contribuindo para o meio ambiente em função de utilizar um resíduo poluente. Assim, neste trabalho foram estudadas três características de desempenho de argamassas mistas de revestimento (densidade de massa aparente no estado fresco e no estado endurecido, absorção de água por capilaridade e perda de água por evaporação), em função da substituição de $4 \%$ e 10\% (em volume) do agregado miúdo por três diferentes granulometrias de borracha de pneus (fina \#0,075 mm, média \#1,19 mm e grossa \#2,38 mm). Os resultados indicaram que as argamassas produzidas com borracha proporcionaram redução no valor da densidade de massa aparente. Quanto à absorção de água por capilaridade, os traços com borracha apresentaram maior absorção que o traço de referência, onde a granulometria grossa foi a que absorveu mais água. Pôde-se observar que todas as argamassas com borracha apresentaram praticamente a mesma taxa de evaporação e percentuais de retenção de água próximos. Tevese como indicativo de melhores resultados a granulometria de borracha média, sendo possível afirmar, contudo, que é necessário ampliar o conhecimento sobre o comportamento de argamassas mistas produzidas com borracha de pneus.

Palavras-chave: Resíduos de pneus, Argamassas mistas, Material alternativo, Meio ambiente.

\section{Introdução}

O avanço tecnológico tem como consequência o aumento na produção de resíduos, devido ao processo de industrialização. Em decorrência disso, surgem diversas discussões a respeito do correto manuseio e descarte de tais resíduos, com um crescente aumento na preocupação ambiental, tanto em nível nacional e internacional.

Um dos tipos mais importantes de resíduos é o de pneus, cuja quantidade a nível mundial tem aumentado devido ao crescimento da indústria automobilística. A utilização dos pneus trouxe consigo a questão de proteção ambiental, pois a grande maioria dos pneus utilizados é abandonada em locais inadequados, constituindo um risco para o ambiente e para a saúde pública.

De maneira paralela, é importante que sejam desenvolvidas técnicas construtivas que diminuam o volume de resíduos de pneus gerados atualmente. De fato, a utilização deste material para a produção de argamassas pode ser uma das alternativas para o problema dos resíduos de pneus. Ainda mais no Brasil, onde há a tradição de se executar os revestimentos das edificações em argamassa. Essa medida gera para a sociedade uma série de benefícios, como a redução do volume de matériasprimas extraídas da natureza, a redução do consumo de energia na produção de materiais e a diminuição da emissão de poluentes no meio ambiente [1].

Alguns trabalhos sobre a produção de argamassas com borracha de pneus demonstram a possibilidade de este material substituir, parcialmente, agregados de origem natural, contribuindo para o meio ambiente em função de utilizar um resíduo poluente e substituí-lo por materiais de fontes naturais finitas [2], [3]. Foram observadas, no entanto, modificações do comportamento das argamassas nos estados fresco e endurecido, em relação às argamassas sem incorporação de borracha de pneus.

De modo geral, os resultados mostram que a produção de argamassas com borracha de pneus implica em uma diminuição significativa na densidade de massa dos compósitos. Além disso, verifica-se que ocorre decréscimo na capacidade de resistência à tração na flexão e também na resistência à compressão [2], [3].

Algumas pesquisas obtiveram resultados satisfatórios quando trabalharam com argamassa de cimento, areia e borracha, fazendo um tratamento para aumentar a aderência entre a borracha e a pasta de cimento [3], [4]. Pesquisa recente sobre 
argamassas incorporadas com pó de borracha de pneus nas proporções $6 \%, 8 \%, 10 \%$ e $12 \%$, com ensaios de resistência à compressão, resistência à flexão, energia de deformação, índice de vazios, absorção de água por capilaridade e resistência à tração na flexão, concluíram que, de um modo geral, a produção de argamassa com adição de pó de borracha é totalmente viável até um limite de incorporação do teor de borracha, sendo de $8 \%$ no caso da argamassa seca em estufa, e no caso da argamassa curada esse teor de incorporação da borracha não pode exceder $6 \%[5]$.

Dessa forma, o objetivo geral deste trabalho foi avaliar experimentalmente argamassas mistas de revestimento produzidas com três diferentes granulometrias de borracha de pneus (\#0,075 mm, \#1,19 mm e \#2,38 mm), por meio de ensaios de densidade de massa aparente (no estado fresco e no estado endurecido), absorção de água por capilaridade e perda de água por evaporação.

\section{Materiais e Métodos}

\subsection{Materiais}

Foram utilizados na composição das argamassas mistas os seguintes materiais: cimento CP II F-32, cal CH-III, areia natural e a borracha de pneus. Foram determinadas as densidades de massa aparente e as densidades de massa absoluta de cada um dos materiais. Os resultados estão apresentados na Tabela 1.

Tabela 1 - Resultados de densidade de massa aparente e absoluta dos materiais.

\begin{tabular}{cccc}
\hline \multirow{2}{*}{ Material } & \multicolumn{2}{c}{$\begin{array}{c}\text { Densidade de massa } \\
\left(\mathbf{g} / \mathbf{c m}^{3}\right)\end{array}$} & Norma \\
\cline { 2 - 3 } & Aparente & Absoluta & \\
\hline $\begin{array}{c}\text { Cimento } \\
\text { CP II F-32 }\end{array}$ & 1,450 & 3,080 & NBR NM 23 [6] \\
\hline Cal & 0,689 & 2,393 & NBR NM 23 [6] \\
CH-III & 1,509 & 2,617 & $\begin{array}{c}\text { NBR NM 45 [7]; } \\
\text { NBR NM 52 [8] }\end{array}$ \\
\hline Areia & 0,320 & 1,150 & $\begin{array}{c}\text { NBR NM 45 [7]; } \\
\text { NBR NM 53 [9] }\end{array}$ \\
\hline $\begin{array}{c}\text { Borracha } \\
\text { de pneus }\end{array}$ & & & \\
\hline
\end{tabular}

As três granulometrias de borracha utilizadas são oriundas do processo mecânico de recauchutagem de pneus de caminhões. Tais resíduos possuem uma composição bastante diversificada em relação as suas dimensões, e sua separação no local de beneficiamento é uma prática inviável. Sendo assim, optou-se por executar a seleção por processo de peneiramento em laboratório.

$\mathrm{O}$ total de aproveitamento dos resíduos de borracha coletados foi de aproximadamente $85 \%$. Assim, $15 \%$ do material restante ficou constituído de pedaços grandes da banda de rodagem dos pneus, ficando excluídos deste estudo. A borracha foi separada em faixas granulométricas bem definidas, apresentando inclusive fácil distinção visual: borracha fina (forma granular tipo pó, passante na peneira \#0,075 mm, Figura 1a); borracha média (formato alongado tipo fibra, com comprimento inferior a $5 \mathrm{~mm}$, passante na peneira $\# 1,19 \mathrm{~mm}$, Figura 1b); e borracha grossa (formato alongado tipo fibra, apresentando comprimentos máximos por volta de $10 \mathrm{~mm}$, passante na peneira \#2,38 mm, Figura 1c).

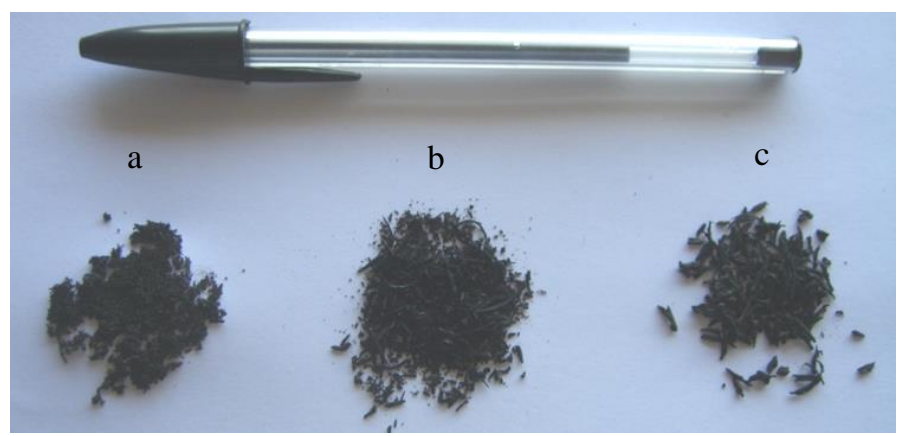

Figura 1 - a) Borracha fina; b) Borracha média; c) Borracha grossa.

\subsection{Composição dos Traços}

Foi adotado o traço em volume de materiais secos (cimento, cal e areia) 1: 1: 5 [10], com substituição parcial de 4\% e $10 \%$ em volume do agregado miúdo por borracha de pneus. O teor de borracha utilizado representa uma quantidade significativa, considerando-se que a massa específica da borracha é baixa. E levando-se em consideração os resultados de pesquisas com borracha de pneus, as mesmas sempre utilizaram compósitos com teores de incorporação que variaram de $3 \%$ a $15 \%$, em volume [2], [3], [11], [12], [13], [14], [15].

Inicialmente, realizou-se a transformação dos traços em volume para massa, sendo que as proporcionalidades dos materiais, em massa, foram definidas a partir dos resultados da densidade de massa do cimento, da cal, da areia e da borracha de pneus. A relação água/ligante utilizada foi de 0,95 . O plano experimental incluiu a execução de quatro traços de argamassas mistas, sendo três com utilização de borracha e um sem a utilização de borracha. As Tabelas 2, 3 e 4 apresentam o quantitativo dos materiais utilizados em cada traço de argamassa mista produzida.

Tabela 2 - Quantidade de materiais utilizados no traço de argamassa controle.

\begin{tabular}{cccc}
\hline \multirow{2}{*}{ Materiais } & \multicolumn{3}{c}{ Consumo de materiais } \\
\cline { 2 - 4 } & $\mathbf{k g} \mathbf{m}^{\mathbf{3}}$ & \% Massa & \% Volume \\
\hline Cimento & 283,89 & 12,23 & 11,93 \\
\hline Areia & 1487,16 & 64,06 & 55,00 \\
\hline Cal & 133,21 & 5,74 & 10,78 \\
\hline Água & 417,10 & 17,97 & 23,29 \\
\hline
\end{tabular}


Tabela 3 - Quantidade de materiais utilizados no traço de argamassa com incorporação de $4 \%$ de borracha.

\begin{tabular}{cccc}
\hline \multirow{2}{*}{ Materiais } & \multicolumn{3}{c}{ Consumo de materiais } \\
\cline { 2 - 4 } & $\mathbf{k g} / \mathbf{m}^{\mathbf{3}}$ & \% Massa & \% Volume \\
\hline Cimento & 283,89 & 12,98 & 11,14 \\
\hline Areia & 1330,14 & 60,83 & 50,13 \\
\hline Cal & 133,21 & 6,09 & 10,99 \\
\hline Borracha & 22,48 & 1,03 & 4,00 \\
\hline Água & 417,10 & 19,07 & 23,74 \\
\hline
\end{tabular}

Tabela 4 - Quantidade de materiais utilizados no traço de argamassa com incorporação de $10 \%$ de borracha.

\begin{tabular}{cccc}
\hline \multirow{2}{*}{ Materiais } & \multicolumn{3}{c}{ Consumo de materiais } \\
\cline { 2 - 4 } & $\mathbf{k g} / \mathbf{m}^{\mathbf{3}}$ & \% Massa & \% Volume \\
\hline Cimento & 283,89 & 13,24 & 10,78 \\
\hline Areia & 1251,63 & 58,38 & 45,63 \\
\hline Cal & 133,21 & 6,21 & 10,63 \\
\hline Borracha & 58,12 & 2,71 & 10,00 \\
\hline Água & 417,10 & 19,45 & 22,96 \\
\hline
\end{tabular}

\subsection{Ensaios do Programa Experimental}

\subsubsection{Densidade de Massa Aparente no Estado Fresco e Endurecido}

A densidade de massa é utilizada para determinar o rendimento da argamassa no estado fresco e influencia significativamente diversas propriedades no estado fresco e endurecido. $\mathrm{O}$ valor da densidade de massa da argamassa no estado endurecido é um indicativo da compacidade resultante da proporção de mistura agregado/ligante e da distribuição granulométrica do conjunto; determina indiretamente o volume de vazios incorporados pela quantidade de água de amassamento perdida por evaporação.

Os ensaios de densidade de massa aparente no estado fresco foram realizados conforme as prescrições da NBR 13278 [16], Figura 2a. A determinação da densidade de massa aparente no estado endurecido foi realizada aos 28 dias, conforme a NBR 13280 [17], Figura 2b. Para cada traço de argamassa mista produzido, foram confeccionados três corpos de prova cilíndricos com dimensões de $50 \mathrm{~mm}$ de diâmetro por $100 \mathrm{~mm}$ de altura. O adensamento dos corpos de prova foi realizado manualmente. As densidades de massa aparente no estado fresco e endurecido foram obtidas através da média aritmética dos resultados com os corpos de prova de cada traço.

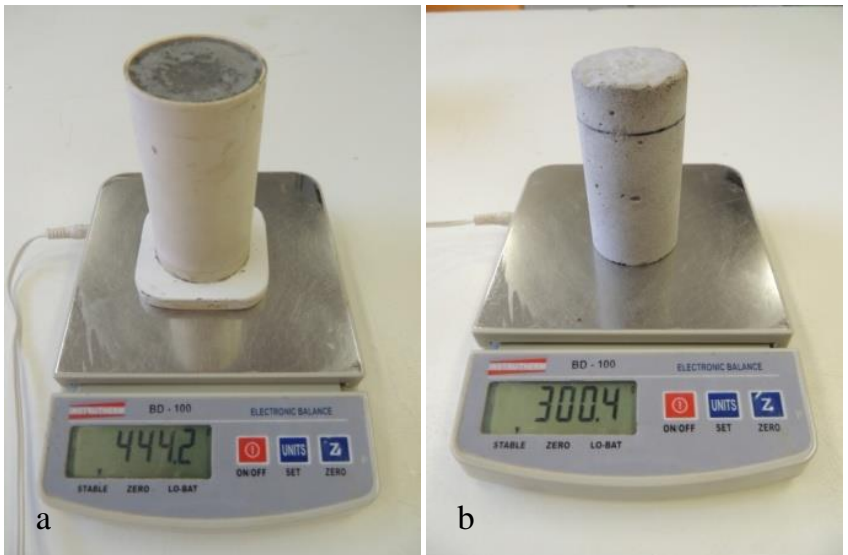

Figura 2 - a) Corpo de prova pesado no estado fresco; b) Corpo de prova pesado no estado endurecido, aos 28 dias.

\subsubsection{Absorção de Água por Capilaridade}

A absorção de água por capilaridade é caracterizada pela passagem de água através da argamassa endurecida por meio de infiltração sob pressão. A permeabilidade é influenciada, essencialmente, pela granulometria da areia, características e proporcionalidades dos materiais constituintes da argamassa, quantidade de água utilizada na mistura e, também, pela utilização de aditivos químicos.

Após 28 dias da data de moldagem, foram selecionados três corpos de prova cilíndricos, de $50 \mathrm{~mm}$ de diâmetro por 100 $\mathrm{mm}$ de altura, de cada traço de argamassa mista produzida para a determinação da absorção de água por capilaridade, conforme a NBR 9779 [18]. O adensamento dos corpos de prova foi manual. Foi adotada como absorção de água por capilaridade a média aritmética dos resultados obtidos durante os ensaios com os corpos de prova de cada traço. A Figura 3 apresenta os corpos cilíndricos utilizados para esta análise.

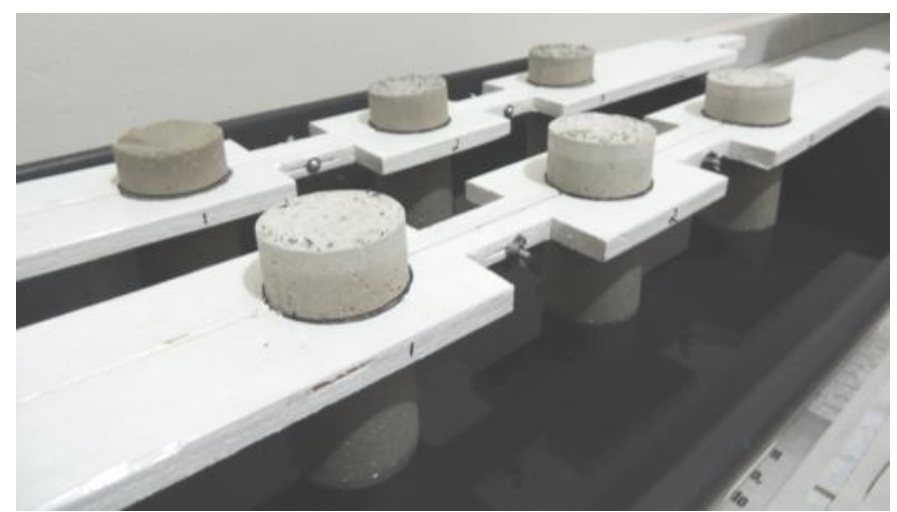

Figura 3 - Realização da absorção de água por capilaridade nas argamassas produzidas. 


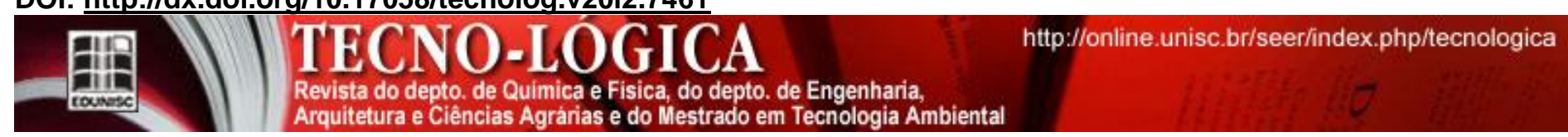

\subsubsection{Perda de Água por Evaporação}

Os revestimentos de argamassas, já nas primeiras horas, sofrem severas ações provenientes do ambiente como temperaturas altas, umidade relativa baixa, ventos fortes que agem sobre o revestimento favorecendo a perda de água por evaporação. É fundamental que a argamassa no estado fresco tenha capacidade de retenção de água reduzindo a perda de água por evaporação.

Neste ensaio foram avaliadas as argamassas mistas após serem colocadas em um recipiente metálico com dimensões internas de $200 \mathrm{~mm} \times 100 \mathrm{~mm}$ x $30 \mathrm{~mm}$, preenchido em duas camadas de mesma espessura, adensadas manualmente. Utilizaram-se duas condições de exposição, onde os recipientes com argamassa mista foram pesados em uma balança de precisão para determinação dos valores da perda de massa com leituras efetuadas nos seguintes intervalos de tempo, em minutos: $0,1,3$, $6,10,15,20,25,30,45,60,75,90,120,180$ e 240 [19]. Foram utilizados dois corpos de prova por traço de argamassa mista produzida, sendo traçado um gráfico de evaporação ao longo do tempo através da Equação (1):

$$
P A_{\text {evaporação }}=\left[1-\left(\frac{M_{\text {conjunto }}-M_{\text {fôrma }}}{M_{\text {argamassa }}}\right)\right] \times 100
$$

sendo: PAevaporação = perda de água por evaporação (\%); Mconjunto $=$ massa do recipiente metálico + massa da argamassa $(\mathrm{g})$; Mfôrma $=$ massa do recipiente metálico (g); e Margamassa $=$ massa da argamassa $(\mathrm{g})$.

No planejamento do experimento adotaram-se duas condições de exposição, onde foi utilizado um corpo de prova para cada uma delas. A primeira exposição crítica foi denominada condição 1 (severa) - com uso de um aparato de madeira com quatro lâmpadas de $100 \mathrm{~W}$, em ambiente protegido, conforme Figura 4. Nesta condição, o recipiente com argamassa foi acondicionado no aparato para secagem, chegando a atingir temperatura superficial máxima de $60 \pm 4^{\circ} \mathrm{C}$. A outra condição foi escolhida para que pudesse servir de referência, com temperatura e umidade relativa controladas, chamada de condição 2 (laboratório) - secagem em ambiente de laboratório, com temperatura de $23 \pm 2{ }^{\circ} \mathrm{C}$ e umidade relativa do ar de $60 \pm$ $5 \%$.

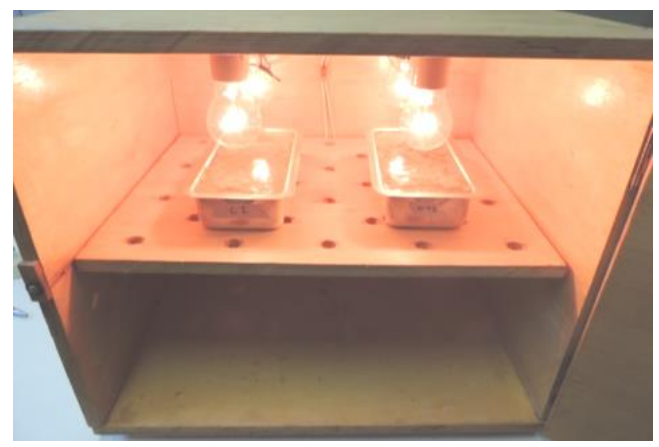

Figura 4 - Aparato utilizado na condição de exposição crítica.

\section{Resultados e Discussões}

\subsection{Densidade de Massa Aparente no Estado Fresco e Endurecido}

A Figura 5 apresenta os resultados de densidade de massa aparente no estado fresco e endurecido.

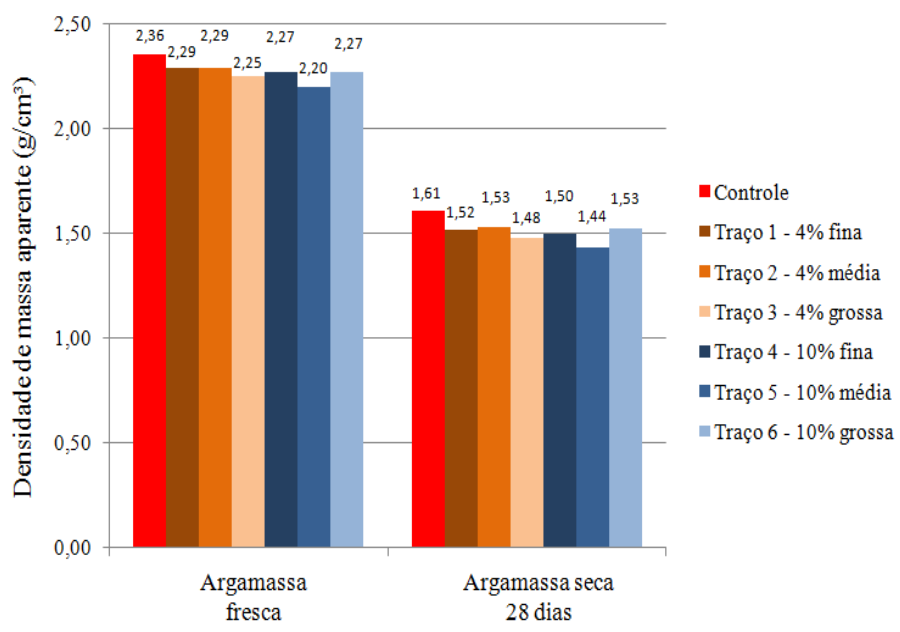

Figura 5 - Densidade de massa aparente das argamassas produzidas x idade.

Os resultados dos ensaios demonstraram que a incorporação de borracha de pneus causa uma redução na densidade de massa das argamassas, o que se explica pelo fato da borracha ser um material leve (menor densidade da borracha em relação à densidade da areia), e também pelo fato de que ao adicionar a borracha na argamassa o teor de ar incorporado tende a aumentar. Diante disso, todos os traços produzidos com a borracha apresentaram valores inferiores ao do traço de referência (controle).

Além disso, o processo de trituração da borracha não tem influência no valor da densidade de massa aparente das argamassas produzidas [5], [13] e [14].

É possível perceber que a incorporação de $4 \%$ e $10 \%$ de borracha nas argamassas apresentou valores relativamente próximos, porém menores do que a argamassa controle.

Com relação às argamassas com incorporação de $4 \%$ de borracha observou-se que no estado fresco a granulometria de borracha grossa apresentou densidade $1,75 \%$ menor quando comparada com as granulometrias de borracha fina e média, que apresentaram os mesmos resultados $\left(2,29 \mathrm{~g} / \mathrm{cm}^{3}\right)$. Já no estado endurecido a argamassa contendo a granulometria de borracha média foi o que apresentou a maior densidade, seguida pelas granulometrias de borracha fina e grossa, com uma diferença de $3,27 \%$ entre a mais densa (com borracha média) e a menos densa (com borracha grossa). 
Com as argamassas contendo $10 \%$ de substituição de borracha, foi possível observar que, no estado fresco, a argamassa produzida com a granulometria de borracha média foi a que apresentou menor densidade quando comparada com as argamassas produzidas com as granulometrias de borracha fina $\mathrm{e}$ grossa, cerca de $3,1 \%$ menor. No estado endurecido ocorreu o contrário do observado nas argamassas com $4 \%$ de substituição, sendo que a argamassa contendo a granulometria de borracha média apresentou densidade 5,9\% menor que a argamassa contendo a granulometria de borracha grossa, que foi a mais densa.

Comparando-se as médias obtidas de cada percentual, podemos observar que houve um leve declínio da densidade com o aumento do percentual de borracha, sendo que no estado fresco as médias das argamassas com $4 \%$ e $10 \%$ de incorporação foram, respectivamente, 2,27 e $2,24 \mathrm{~g} / \mathrm{cm}^{3}$; e no estado endurecido foram 1,51 e $1,49 \mathrm{~g} / \mathrm{cm}^{3}$.

\subsection{Absorção de Água por Capilaridade}

Os resultados dos ensaios de absorção de água por capilaridade são apresentados na Figura 6.

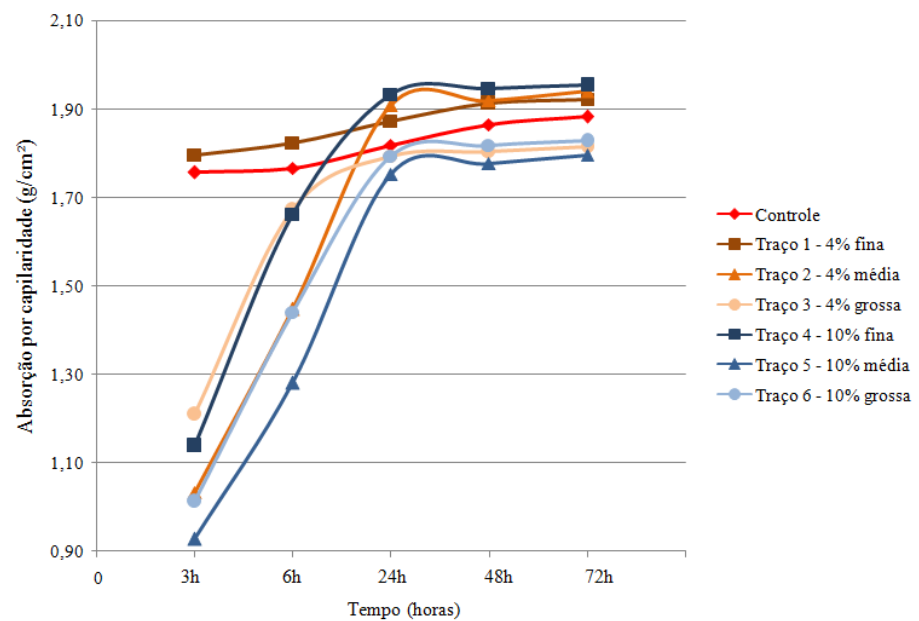

Figura 6 - Permeabilidade à água dos traços das argamassas em função do tempo.

Pelo gráfico da Figura 6, podemos observar que o traço controle e o traço 1 apresentam resultados similares, mantendo praticamente constante a absorção de água durante as 72 horas de tempo de ensaio.

Observou-se que conforme foi aumentada a porcentagem e a granulometria de borracha incorporada, a tendência das argamassas era de iniciar o ensaio com uma absorção mais baixa (3 horas) que os dois traços iniciais (controle e traço 1), mas que nas primeiras 24 horas de ensaio absorviam um maior volume de água. No final (entre 24 e 72 horas), todos os traços se mantiveram constantes, quase que igualados e alguns deles até mesmo ultrapassaram os dois primeiros traços.
A média de absorção do traço 1 (4\% de borracha fina) foi a maior $\left(1,87 \mathrm{~g} / \mathrm{cm}^{2}\right)$, ultrapassando o traço controle $\left(1,82 \mathrm{~g} / \mathrm{cm}^{2}\right)$. $\mathrm{O}$ traço 5 foi o que obteve a menor média de absorção (10\% de borracha média) com média de $1,51 \mathrm{~g} / \mathrm{cm}^{2}$, com uma diferença inicial média entre eles de $0,36 \mathrm{~g} / \mathrm{cm}^{2}$.

Percebeu-se também que nesse ensaio a granulometria de borracha média foi a que teve a menor absorção em ambos os percentuais de substituição. Como também pode ser notado que as argamassas com incorporação de granulometria grossa de borracha tiveram um comportamento diferenciado das demais. Foi possível observar uma saturação mais rápida nas argamassas com borracha grossa, ou seja, ela estabiliza a absorção de água mais cedo do que as argamassas com borracha média. Porém, não podemos afirmar que este é um material mais poroso.

Apresentando em números, a granulometria fina no total teve uma absorção média de $1,75 \mathrm{~g} / \mathrm{cm}^{3}$; a granulometria média de $1,53 \mathrm{~g} / \mathrm{cm}^{3}$ e a granulometria grossa de $1,61 \mathrm{~g} / \mathrm{cm}^{3}$. Pode-se observar que as argamassas que incorporaram a granulometria de borracha média absorveram menos água do que as demais, aproximadamente $4,97 \%$ menor do que as argamassas com granulometria de borracha grossa, de $12,58 \%$ menor que as argamassas com granulometria de borracha fina, e de 15,94\% menor do que a argamassa controle.

Pesquisas que analisaram diferentes granulometrias de borracha de pneus no concreto, concluíram que a capacidade de absorção de água sofreu interferência com as dimensões das partículas de borracha, pois para as granulometrias mais finas a absorção de água foi menor [3], [12].

Outra pesquisa que avaliou a permeabilidade à água, concluiu que esta propriedade apresenta valores muito semelhantes nos diferentes tipos de argamassas produzidas com borracha de pneus [2]. Estes resultados podem ser explicados pelo fato da incorporação de borracha provocar um aumento do teor de ar incorporado, levando a uma baixa compactação devida à diminuição da densidade de massa das argamassas. Desta forma, estes dois efeitos contraditórios equilibram-se originando valores idênticos nas diferentes argamassas.

\subsection{Perda de Água por Evaporação}

Os resultados dos ensaios para determinação da perda de água das argamassas, nas duas condições de exposição, são apresentados na Figura 7. 


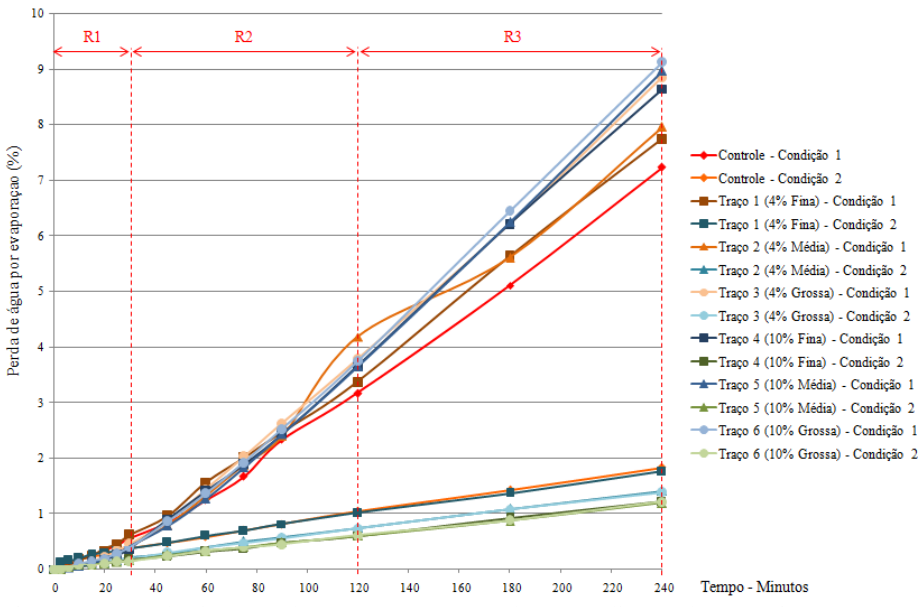

Figura 7 - Perda de água das argamassas nas duas condições de exposição.

Os resultados obtidos pelas argamassas incorporadas com granulometria fina mostraram que, entre aquelas mantidas em estufa (condição 1), a que apresentou maior perda de água foi a com incorporação de $10 \%$ de borracha, com uma taxa média de evaporação de $1,63 \%$, seguida por aquelas com incorporação de $4 \%$ de borracha $(1,60 \%)$ e a argamassa do traço controle $(1,46 \%)$. Isso demonstra que a perda de água das argamassas em situação severa é maior nas argamassas contendo borracha do que na argamassa controle.

Com relação às argamassas incorporadas com borracha de granulometria média os resultados foram parecidos com o que a as argamassas de borracha fina apresentaram. A que continha $10 \%$ de borracha foi a que apresentou maior perda de água, seguida pela argamassa com $4 \%$ de borracha e o traço controle, com taxas de evaporação média de 1,64\%, 1,58\% e 1,46\%, respectivamente. $\mathrm{O}$ que indica uma contribuição da borracha na tendência da argamassa a perder mais água.

Os resultados obtidos pelas argamassas com incorporação de borracha grossa foram parecidos entre os dois percentuais estudados, mostrado no gráfico da Figura 7, quase que sobrepondo as linhas das respectivas argamassas. Apenas aos 160 minutos de ensaio que a argamassa com $4 \%$ de borracha teve uma leve queda na perda de água em relação à argamassa com $10 \%$ de incorporação de borracha. A taxa média de absorção da argamassa com $4 \%$ de borracha foi de $1,69 \%$ e a com $10 \%$ de borracha foi de $1,70 \%$.

Já as argamassas em condição de laboratório apresentaram duas situações diferentes para os três tipos de granulometrias empregadas. A argamassa controle e as argamassas com $4 \%$ de borracha tiveram resultados muito parecidos, com taxas de evaporação de $0,52 \%$ para ambas, que pode ser observado no gráfico da Figura 7, além de apresentarem maior perda de água em relação ao outro traço estudado. As argamassas contendo $10 \%$ de borracha apresentaram menor perda de água nessa condição, esse resultado se repetiu para as três granulometrias estudadas $(0,29 \%)$. Observou-se que a situação se inverte a da condição severa, já que a argamassa com maior percentual de borracha foi aquela que menos perdeu água para o ambiente.

Os perfis da perda de água traçados na Figura 6 para as duas condições de exposição, de um modo geral, apresentam o mesmo comportamento, diferenciando-se, na maioria dos casos, apenas no percentual do volume de água transportado. Pode-se observar que existem três regimes (R1, R2 e R3). O regime R1 está compreendido no intervalo de tempo de 0 a $30 \mathrm{~min}$; o regime $\mathrm{R} 2$, entre 30 e $120 \mathrm{~min}$; e o regime R3, de 120 a $240 \mathrm{~min}$. A inclinação mais acentuada indica maior perda de água. Por sua vez, a menor inclinação denota menor intensidade dessa perda.

Com relação a todos os traços produzidos e ensaiados, pode-se perceber uma visível diferença entre as retas que representam as condições em que as argamassas foram submetidas, sendo que na condição 1 (severa) as argamassas foram mantidas em um aparato simulando uma estufa, e na condição 2 (laboratório) as argamassas foram mantidas em ambiente de laboratório, com temperatura ambiente em torno de $23^{\circ} \mathrm{C}$. Ao final dos ensaios, as argamassas da condição 1 se encontravam completamente secas, sendo que algumas delas até apresentavam uma fenda de retração devido à secagem excessiva. Já as argamassas em condição 2 apresentavam-se bastante úmidas, com uma camada fina de água sobre a superfície, causada pelo fenômeno conhecido como exsudação, que é o fenômeno migratório da água existente na composição para a superfície do material.

\section{Conclusões}

As argamassas produzidas com borracha de pneus proporcionaram uma redução no valor da densidade de massa aparente, tanto no estado fresco como no endurecido. Concluiuse que dentro da faixa das granulometrias estudadas, a mesma não teve influência nos resultados, pois o mesmo ocorreu quando se comparou argamassa fresca e argamassa seca aos 28 dias, ficando os valores quase que constantes.

Foi observado que o uso de borracha de pneus altera a propriedade de absorção de água por capilaridade nas argamassas de revestimento, pois os traços de argamassas com incorporação de borracha obtiveram taxas médias de absorção de água maiores que a taxa média de absorção da argamassa de referência. Verificou-se que a argamassa produzida com a granulometria de borracha média foi a que apresentou, inicialmente, a menor taxa média de absorção de água, indicando que não se pode afirmar que houve uma redução no desempenho dessa propriedade em função da granulometria utilizada, mas confirmar controvérsias das literaturas.

Com relação à perda de água por evaporação, os traços de argamassa com borracha de pneus na condição severa apresentam maiores velocidades de perda de água, enquanto na condição de laboratório os traços de argamassa com borracha tiveram menor 
perda de água. Pôde-se observar que as argamassas com incorporação de borracha apresentaram praticamente a mesma taxa de evaporação e percentuais de retenção de água próximos, mesmo sem a presença de aditivos e, de certa maneira, apresentando um elevado volume de ar. Por meio da comparação realizada entre a condição de exposição severa com a condição de exposição mais amena, ficou evidenciada a necessidade de se atenuar os fatores que aceleram a perda de água das argamassas de revestimento com incorporação de borracha. Cabe ressaltar que os cuidados devem ser iniciados nos momentos pósaplicação das argamassas.

Por fim, teve-se como indicativo de melhores resultados avaliando todos os ensaios, a granulometria de borracha média. É possível afirmar, contudo, que é necessário ampliar o conhecimento sobre o comportamento de argamassas para aplicação em revestimentos produzidas com borracha de pneus.

\section{Agradecimentos}

FAPESP - Fundação de Amparo à Pesquisa do Estado de São Paulo, pela concessão do auxílio financeiro.

\section{EVALUATION OF MIXED COATING MORTARS PRODUCED WITH RUBBER TIRES}

\begin{abstract}
Studies on production of tire rubber with mortar demonstrate the possibility of this material partially replace, aggregate of natural origin, contributing to the environment due to use a polluting waste. This study aimed to analyze three performance characteristics of composite mortar coating (apparent bulk density of the fresh and hardened state, capillary water absorption and water loss by evaporation), due to the replacement of $4 \%$ and $10 \%$ (by volume) the fine aggregate for three different tires rubber particle sizes (fine \#0,075 mm, media $\# 1,19 \mathrm{~mm}$ and thick \#2,38 $\mathrm{mm}$ ). The results indicated that the mortars produced with rubber tires provide reduction in the amount of apparent bulk density. As for the absorption of water by capillarity, traces rubber tires showed greater absorption than the mark where the thick particle size was that absorbed more water. It was observed that all mortars with rubber tires had almost the same rate of evaporation and near water retention percentage. This study had as indicative of better results the media rubber particle size, which can be said, however, that it is necessary to increase knowledge about the behavior of mixed mortars produced with rubber tires.
\end{abstract}

Keywords: Residues tires, Mixed mortars, Alternative materials, Environment.

\section{Referências}

[1] RODRIGUES, M. R. P.; FERREIRA, O. P. Compósito cimentício com adição de partículas de borracha de pneus inservíveis. Revista Minerva - Pesquisa \& Tecnologia, Vol. 3, n. 3, p. 255-261. 2009.

[2] PEDRO, D. A. G. Desempenho de argamassas fabricadas com incorporação de materiais finos provenientes da trituração de pneus. 2011, 155 f. Dissertação (Mestrado) - Instituto Superior Técnico da Universidade Técnica de Lisboa, Lisboa, 2011

[3] TRIGO, A. P. M.; MARQUES, A. C.; AKASAKI, J. L.; MARINHO, J. R. D. Argamassa com adição de resíduos de borracha submetida à elevada temperatura. In: CONGRESSO BRASILEIRO DO CONCRETO, 47, 2005, Olinda. Anais... Olinda: IBRACON, p. 55-63.

[4] SEGRE, N. et al. Rubber-mortar composites: effect of composition on properties. Journal of Materials Science, Vol. 39, n. 10, p. 3319-3327, 2004.

[5] CANOVA, J. A.; BERGAMASCO, R.; ANGELIS NETO; G. DE; GLEIZE, P. J. P. Comparative analysis of the properties of composite mortar with addition of rubber powder from worn tires. Ambiente Construído, Porto Alegre, Vol. 12, n. 1 , p. $257-267.2012$.

[6] ASSOCIAÇÃO BRASILEIRA DE NORMAS TÉCNICAS. NBR NM 23: Cimento Portland e outros materiais em pó - Determinação da massa específica. Rio de Janeiro, 2001

[7] ASSOCIAÇÃO BRASILEIRA DE NORMAS TÉCNICAS. NBR NM 45: Agregados - Determinação da massa unitária e do volume de vazios. Rio de Janeiro, 2006.

[8] ASSOCIAÇÃO BRASILEIRA DE NORMAS TÉCNICAS. NBR NM 52: Agregado miúdo - Determinação de massa específica e massa específica aparente. Rio de Janeiro, 2009.

[9] ASSOCIAÇÃO BRASILEIRA DE NORMAS TÉCNICAS. NBR NM 53: Agregado graúdo - Determinação da massa específica, massa específica aparente e absorção de água. Rio de Janeiro, 2003.

[10] THOMAZ, E. Tecnologia, gerenciamento e qualidade na construção civil. São Paulo: Editora Pini, 2001.

[11] RAGHVAN, D.; HUYNH, H.; FERRARIS, C. F. Workability, mechanical properties, and chemical stability of a recycled tyre rubber-fillet cementations composite. Journal of Materials Science, Vol. 33, p. 1745-1752, 1998.

[12] FIORITI, C. F. Pavimentos intertravados de concreto utilizando resíduos de pneus como material alternativo. 2007. 202 f. Tese (Doutorado) - Escola de Engenharia de São Carlos da Universidade de São Paulo, São Carlos, 2007.

[13] TURATSINZE, A.; BONNET, S.; GRANJU, J. L. Potential of rubber aggregates to modify properties of cement based-mortars: improvement in cracking shrinkage resistance. Construction and Building Materials, Vol. 21, n. 1, p. 176-181, 2007.

[14] TOPÇU, I. B.; DEMIR, A. Durability of rubberized mortar and concrete. Construction and Building Material, January, Vol. 21, p. 176-181, 2007.

[15] TURKI, M.; BRETAGNE, E.; ROUIS, M. J.; QUÉNEUDEC, M. Microstructure, physical and mechanical properties of mortar-rubber aggregates mixtures. Construction and Building Materials, Vol. 23, n. 7, p. 2715-2722, 2009.

[16] ASSOCIAÇÃO BRASILEIRA DE NORMAS TÉCNICAS. NBR 13278: Argamassa para assentamento e revestimento de paredes e tetos - Determinação da densidade de massa e do teor de ar incorporado. Rio de Janeiro, 2005.

[17] ASSOCIAÇÃO BRASILEIRA DE NORMAS TÉCNICAS. NBR 13280: Argamassa e concreto endurecidos - Determinação da densidade de massa aparente no estado endurecido. Rio de Janeiro, 2005. 


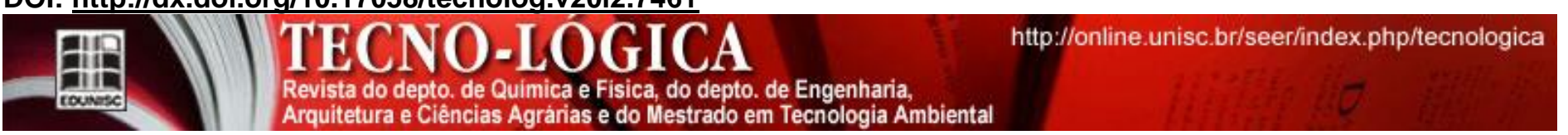

[18] ASSOCIAÇÃO BRASILEIRA DE NORMAS TÉCNICAS. NBR 9779: Argamassa e concreto endurecidos - Determinação da absorção de água por capilaridade. Rio de Janeiro, 2012.

[19] PEREIRA, C. H.; BAUER, E. Perda de água de argamassas de revestimento nos momentos iniciais por evaporação e absorção do substrato. Material and Material, Artigo Técnico 23, 2013. 